\title{
Effect of Ischemic Preconditioning and Mitochondrial KaTP Channel Openers on Chronic Left Ventricular Remodeling in the Ischemic-Reperfused Rat Heart
}

\author{
Yuka Dairaku, MD; Toshiro Miura, MD; Nozomu Harada, MD; \\ Masayasu Kimura, MD; Takayuki Okamura, MD; Hiroshi Iwamoto, MD; \\ Ryosuke Kametani, MD; Michio Yamada, MD; Yasuhiro Ikeda, MD; \\ Mitsuo Iwatate, MD; Shuji Kawamura, MD; Masunori Matsuzaki, MD
}

\begin{abstract}
The influence of ischemic preconditioning (IP) and mitochondrial ATP-sensitive potassium (mito-KATP) channel openers on chronic left ventricular (LV) remodeling remains unknown, so the effect of IP and mito-KATP channel openers on the LV pressure-volume curve was assessed in rats subjected to $30 \mathrm{~min}$ ischemia followed by a 3week reperfusion. Infarct size was histologically determined at 3 weeks after reperfusion. The LV pressurevolume curve was significantly shifted left by IP, diazoxide and nicorandil compared with the controls. These effects were blocked by the selective mito-KATP channel blocker 5-hydroxydecanoate. The LV remodeling and the infarct size at 3 weeks after reperfusion correlated well, indicating that the reduction of LV remodeling in the ischemic - reperfused model was strongly influenced by attenuation of the ischemic injury. LV remodeling in the chronic phase is attenuated by IP and mito-KATP channel openers with concomitant reduction of infarct size. (Circ J 2002; 66: 411-415)
\end{abstract}

Key Words: Diazoxide; Ischemic preconditioning; Nicorandil; Pressure-volume curve

A

brief episode of ischemia-reperfusion reduces the size of the infarct caused by a subsequent longer ischemia-reperfusion insult. This phenomenon was first reported by Murry et $\mathrm{al}^{1}$ and termed ischemic preconditioning (IP). The underlying mechanism of this phenomenon has been intensively investigated and one of the crucial mechanisms is the opening of the mitochondrial ATP-sensitive potassium (mito-KATP) channels ${ }^{2-4}$ In order to mimic IP, the effect of mito-KATP channel openers has been investigated and these agents result in reduction of infarct size ${ }^{5-12}$ However, the effect of IP and mito-KATP channel openers on chronic left ventricular (LV) remodeling has not been clarified yet. LV remodeling is a major determinant of prognosis after myocardial infarction ${ }^{13}$ and it may be determined by the infarct size and could be modified by drugs such as angiotensin-converting enzyme inhibitors 14 Thus, assessing LV remodeling is an important evaluation of whether or not interventions such as IP or mito-KATP channel openers are really effective. Furthermore, the reperfusion conditions, such as the no reflow phenomenon, may modify the infarct size and thus the LV remodeling in the chronic state. Therefore, the purpose of the present study was to investigate the effect of IP and mito-KATP channel openers on the extent of LV remodeling as assessed by the pressure-volume relationship, and to assess the correlation between infarct size and LV remodel-

(Received October 26, 2001; revised manuscript received December 25, 2001; accepted January 9, 2002)

Department of Cardiovascular Medicine, Medical Bioregulation, Yamaguchi University School of Medicine, Ube, Japan

Mailing address: Masunori Matsuzaki, MD, The Division of Cardiovascular Medicine, Yamaguchi University, School of Medicine, 1-1-1 Minami-Kogushi, Ube 755-8505, Japan. E-mail: masunori@po.cc. yamaguchi-u.ac.jp ing during the chronic stage.

\section{Methods}

All experiments were performed in accordance with the Guide for the Care and Use of Laboratory Animals (NIH Publication No. 85-23) and were approved by the Animal Research Committee of Yamaguchi University School of Medicine.

\section{Surgical Preparation}

Male Sprague-Dawley rats $(280-330 \mathrm{~g})$ were anesthetized by intraperitoneal injection of sodium pentobarbital $(60 \mathrm{mg} / \mathrm{kg})$. Additional anesthesia was given during the experiment as required. After tracheal intubation, the rats were ventilated with a mixture of room air and $100 \%$ oxygen (respiratory rate, $65-70$ breaths/min). After a thoracotomy in the fourth intercostal space, the heart was exposed and a thread was passed around the left anterior descending coronary artery (LAD) to occlude it. After 3 weeks of reperfusion, LV pressure (LVP) was measured by a $2 \mathrm{~F}$ catheter-tip micromanometer (Model SPC-320, Millar Instruments, USA) inserted via the right carotid artery. The peak of the first derivative of LVP $(+\mathrm{dP} / \mathrm{dt})$ and the time constant of isovolumetric LVP decay (Tau) were calculated by an online data acquisition system (CODAS, DATAQ Instruments, Achron, OH, USA). The body temparature was maintained at $37 \pm 0.3^{\circ} \mathrm{C}$ by a heating pad.

\section{Reagents}

Diazoxide (Funakoshi, Osaka, Japan) was dissolved in dimethylsulfoxide (DMSO), the final concentration of which was less than $0.1 \%$. Nicorandil (Chugai, Tokyo, Japan) was dissolved in saline at a concentration of 1.0 


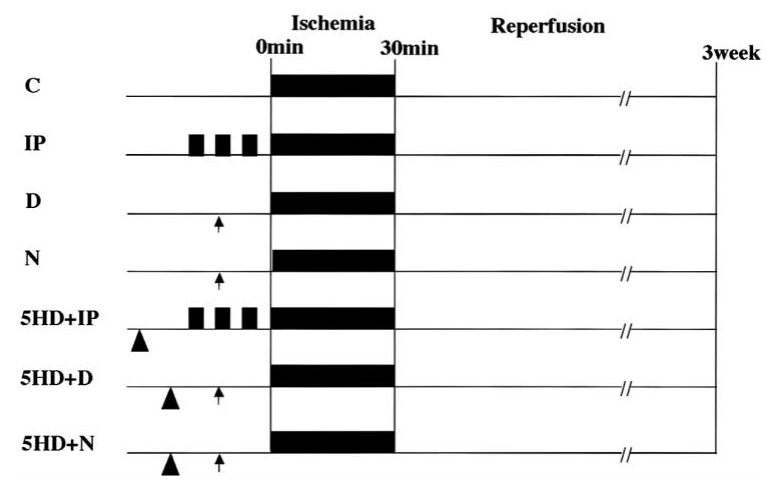

Fig 1. Rats were subjected to a 30-min coronary occlusion followed by 3 weeks of reperfusion in all groups ( $n=6$, each). Ischemic preconditioning (IP) was performed by 3 cycles of $3 \mathrm{~min}$ of ischemia followed by $3 \mathrm{~min}$ of reperfusion. Diazoxide $(3.5 \mathrm{mg} / \mathrm{kg} \mathrm{IV})$ and nicorandil $(1.75 \mathrm{mg} / \mathrm{kg} \mathrm{IV})$ were administered $10 \mathrm{~min}$ before the $30-\mathrm{min}$ ischemia (arrow). 5-hydroxydecanoate $(5.0 \mathrm{mg} / \mathrm{kg} \mathrm{IV})$ was administered $10 \mathrm{~min}$ before IP or the infusion of diazoxide or nicorandil (arrowheads). C, controls; IP, ischemic preconditioning; D, diazoxide; $\mathrm{N}$, nicorandil; 5HD, 5-hydroxydecanoate.

$\mathrm{mg} / \mathrm{ml}$. A selective mito-KATP channel inhibitor, 5-hydroxydecanoate (HD) (Sigma), $2,9,15,16$ was dissolved in saline.

\section{Experimental Protocols}

The experimental protocols are shown in Fig 1. Seven groups of rats $(n=6$, each) were subjected to $30 \mathrm{~min}$ ischemia created by occluding the $\mathrm{LAD}$, followed by reperfusion for 3 weeks. IP was performed by 3 cycles of 3 min of ischemia followed by $3 \mathrm{~min}$ of reperfusion. Diazoxide $(3.5 \mathrm{mg} / \mathrm{kg} \mathrm{IV})$ and nicorandil $(1.75 \mathrm{mg} / \mathrm{kg} \mathrm{IV})$ were injected $10 \mathrm{~min}$ before the $30-\mathrm{min}$ ischemia. 5-HD $(5.0 \mathrm{mg} / \mathrm{kg} \mathrm{IV})$ was administered $10 \mathrm{~min}$ before either IP or diazoxide or nicorandil.

\section{Quantitation of Infarct Size}

Three weeks after the coronary reperfusion, the LAD was re-occluded and trypan blue dye $(1.5 \%, 1 \mathrm{ml}$, Sigma Chemical, Co, St Louis, MO, US) was injected into the ascending aorta to delineate the risk and non-risk area in the hearts. The hearts were then excised and sliced into sections approximately $1 \mathrm{~mm}$ in width. Each slice was imaged by a color CCD camera (FV-10, Fuji, Japan), and the images were analyzed by image analyzing software (NIH image). The area unstained by the blue dye is the area at risk. The heart was fixed in $10 \%$ phosphate-buffered formalin, processed and embedded in paraplast. Transverse sections $(4 \mu \mathrm{m})$ were stained by the modified azan staining. The area of infarction was identified histologically and the infarct size expressed as a percentage of the area at risk.

\section{Pressure-Volume Relation}

According to the method of Pffefer et al, 17 the in vitro LV pressure-volume curve was measured. In brief, the heart was arrested by an infusion of $\mathrm{KCl}$ and then quickly excised. A double-lumen catheter was inserted into the left ventricle, which was isolated by ligating the atrioventricular groove. The right ventricle was incised to eliminate the compressive effect. The left ventricle was emptied by evacuation through the catheter with manual compression. Reproducible pressure-volume curves were generated over a pressure range of $10-30 \mathrm{mmHg}$ by infusing saline at a speed of $0.6 \mathrm{ml} / \mathrm{min}$. These procedures were performed within $10 \mathrm{~min}$ of cardiac arrest and before the onset of rigor mortis. The volume index (volume/body weight) of the respective LVP at 10, 20 and $30 \mathrm{mmHg}$ was assessed.

\section{Statistical Analysis}

All values are expressed as the mean \pm SE. Differences in hemodynamic parameters among the groups were analyzed by 2-way ANOVA. Fisher's test was used when a significant $F$ value was obtained. Inter-group differences in area at risk, infarct size and left ventricular volumes of pressurevolume curves were analyzed by 1-way ANOVA followed by Fisher's test. Correlation between infarct size and the extent of LV remodeling was expressed as LV volume index (volume/body weight) at LVP of $20 \mathrm{mmHg}$ was assessed by linear regression analysis with comparison of the 2 regression parameters of slope and intercept. Differences were considered significant at $\mathrm{p}<0.05$.

\section{Results}

\section{Hemodynamic Responses}

Hemodynamic data at 3 weeks after reperfusion are presented in Table 1. Heart rate, peak LVP, end-diastolic LVP, (+) dP/dt, and Tau were not significantly different among the groups.

\section{Infarct Size}

In the acute phase, $15 \%$ of animals died of technical problems such as pneumotharax and bleeding, but no death from heart failure occurred. In the chronic phase, no deaths occurred. Risk area was not statistically different among the groups (Fig 2A). As shown in Fig 2B, infarct size was significantly reduced by IP $(16 \pm 1 \%, \mathrm{p}<0.01$ vs controls), compared with the controls $(72 \pm 4 \%)$, and by both diazoxide $(40 \pm 4 \%, \mathrm{p}<0.05$ vs controls) and nicorandil $(28 \pm 2 \%$, $\mathrm{p}<0.01$ vs controls). The effect of IP, diazoxide and nico-

Table 1 Hemodynamics After 3-Weeks of Repefusion

\begin{tabular}{|c|c|c|c|c|c|}
\hline & $\begin{array}{c}H R \\
\text { (beats/min) }\end{array}$ & $\begin{array}{c}\text { Peak LVP } \\
(m m H g)\end{array}$ & $\begin{array}{l}\text { LVEDP } \\
(m m H g)\end{array}$ & $\begin{array}{l}(+) d P / d t \\
(m m H g / s)\end{array}$ & $\begin{array}{l}\text { Tau } \\
\text { (ms) }\end{array}$ \\
\hline$C$ & $395 \pm 17$ & $113 \pm 1$ & $5 \pm 4$ & $7,721 \pm 768$ & $12 \pm 1$ \\
\hline$I P$ & $410 \pm 5$ & $115 \pm 7$ & $7 \pm 2$ & $6,215 \pm 1,207$ & $14 \pm 1$ \\
\hline$D$ & $440 \pm 5$ & $97 \pm 1$ & $4 \pm 1$ & $7,643 \pm 377$ & $10 \pm 1$ \\
\hline$N$ & $395 \pm 11$ & $98 \pm 3$ & $4 \pm 1$ & $8,228 \pm 524$ & $10 \pm 1$ \\
\hline $5 H D+I P$ & $378 \pm 5$ & $90 \pm 2$ & $4 \pm 2$ & $7,015 \pm 196$ & $12 \pm 1$ \\
\hline $5 H D+D$ & $419 \pm 10$ & $96 \pm 7$ & $9 \pm 3$ & $7,270 \pm 731$ & $17 \pm 3$ \\
\hline $5 H D+N$ & $430 \pm 11$ & $98 \pm 6$ & $5 \pm 1$ & $8,158 \pm 834$ & $11 \pm 1$ \\
\hline
\end{tabular}

$H R$, heart rate; LVP, left ventricular pressure; LVEDP, left ventricular end-diastolic pressure; $(+) d P / d t$, maximum rate of LVP generation; Time constant, time constant of the LVP fall during isovolumic relaxation period. Other abbreviations are the same as in Fig 1. Values are mean $\pm S E$. $N=6$, each. 
A

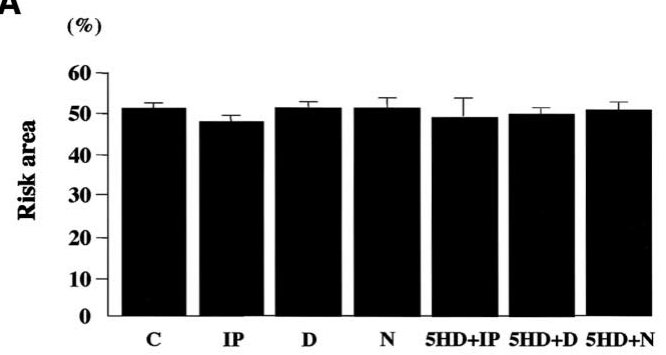

B

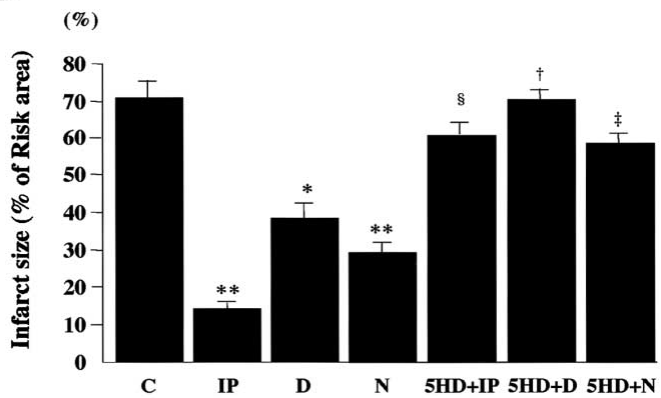

Fig 2. (A) The risk area was identical in all groups. (B) Infarct size was reduced by IP, D, and $\mathrm{N}$ compared with $\mathrm{C}$. The effect of IP, D and $\mathrm{N}$ was abolished by 5 -HD. ${ }^{*} \mathrm{p}<0.05$ vs $\mathrm{C},{ }^{* *} \mathrm{p}<0.01$ vs $\mathrm{C},{ }^{{ }_{\mathrm{p}}}<0.05$ vs IP, ${ }^{\dagger}<<0.05$ vs D, ${ }^{\ddagger} \mathrm{p}<0.05$ vs N. All abbreviations as in Fig 1 .

randil on infarct size was inhibited by 5 -HD $(61 \pm 2 \%$ $\mathrm{p}<0.05$ vs IP, $72 \pm 3 \% \mathrm{p}<0.05$ vs diazoxide, $60 \pm 2 \% \mathrm{p}<0.05$ vs nicorandil).

\section{In Vitro LV Pressure-Volume Relation}

The in vitro LV pressure-volume curve shifted left with IP compared with the controls (Fig 3). With diazoxide or nicorandil, the pressure-volume curve also significantly shifted left compared with the controls. Indeed, the left shift of the LV pressure-volume curve by IP, diazoxide or nicorandil was abolished by $5-\mathrm{HD}$.

\section{Correlation Between the Infarct Size and LV Remodeling}

Linear regression analysis revealed a good correlation between the infarct size (\% of area at risk) and the extent of LV remodeling expressed as the LV volume index (volume/body weight) at a LVP of $20 \mathrm{mmHg}$. The slope of the correlation was $0.014(\mathrm{r}=0.78, \mathrm{p}<0.001)$ (Fig 4).

\section{Discussion}

One of the major findings of the present study is that IP attenuates LV remodeling concomitant with a reduction in infarct size in the chronic stage. Although the reduction of infarct size by IP has been demonstrated in the acute phase (ie, 4-6h after the reperfusion determined by TTC staining) $)^{2,18-23}$ it has not been clear whether IP attenuates LV remodeling. Our study is the first to demonstrate that LV remodeling was attenuated by IP according to the reduction of the size of the histologically determined infarct. Cohen et al showed an improvement in the function of the ischemic myocardium $24 \mathrm{~h}$ after reperfusion in a rabbit model of ischemia-reperfusion. ${ }^{24}$ However, they focused only on the ischemic area, and the change in the remote area was not determined. Our study clearly showed that using pressurevolume relation the whole $\mathrm{LV}$ chamber remodeling was estimated.

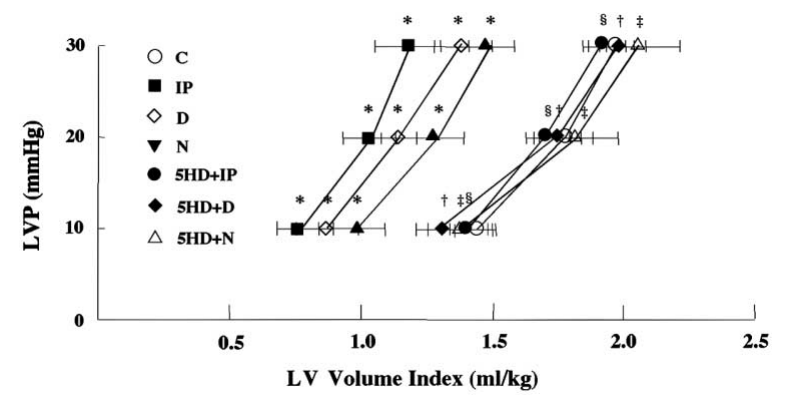

Fig 3. The left ventricular pressure-volume curve was significantly shifted leftward by IP, D, and N compared with C. The shift in the curve caused by IP, D and N was abolished by $5 \mathrm{HD}(\mathrm{n}=6$ each). Data are shown as mean \pm SE. ${ }^{*} \mathrm{p}<0.05$ vs $\mathrm{C},{ }_{\mathrm{p}}<0.05$ vs IP, ${ }^{\dagger}<0.05$ vs $5 \mathrm{HD}+\mathrm{D},{ }_{\mathrm{p}}<0.05$ vs the $5 \mathrm{HD}+\mathrm{N}$. All abbreviations as in Fig 1 .

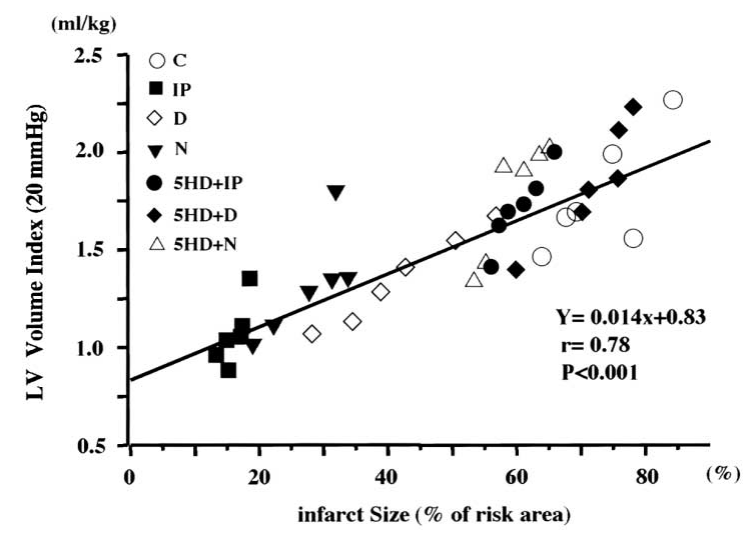

Fig 4. Linear regression analysis revealed a good correlation between the infarct size (\% of area at risk) and the extent of remodeling expressed as LV volume $(\mathrm{ml} / \mathrm{kg})$ at $\mathrm{LV}$ pressure of $20 \mathrm{mmHg}$. The slope of the correlation is $0.014(\mathrm{r}=0.78, \mathrm{p}<0.001)$. All abbreviations as in Fig 1.

The infarct size determined by TTC staining correlates with the histologically determined infarct in the permanent coronary occlusion model 25 However, in the ischemiareperfusion model, the infarct size in the chronic stage may be influenced by the perfusion conditions; the no-reflow phenomenon increases the infarct size in the chronic stage in large animals and humans, ${ }^{26-28}$ and Shimizu et al demonstrated that no-reflow occurs in the isolated rat heart ${ }^{29}$ Furthermore, no-reflow is demonstrated in the skeletal muscle in rat and that is attenuated by IP ${ }^{30}$ So, the effect of IP or drugs on infarct size may differ between the acute and chronic stages. The infarct size may be determined within $6 \mathrm{~h}$ of reperfusion, but it should be taken into consideration that the infarct size determined by TTC after $6 \mathrm{~h}$ of reperfusion was smaller than that determined histologically at 3

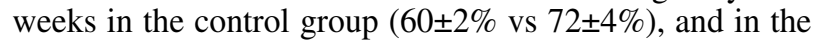
IP group the size of the infarct at 3 weeks was smaller than that after $6 \mathrm{~h}$ of reperfusion $(16 \pm 1 \%$ vs $26 \pm 2 \%) ?^{31}$ This suggests that infarct size may be influenced by the reflow conditions.

It has been shown that attenuation of LV remodeling is a major determinant of survival after acute myocardial infarction although its underlying mechanism is not well understood 13,32 Pffefer et al showed that captopril attenuated LV dilatation after myocardial infarction in a permanent coronary occlusion model 33,34 In their study, infarct 
size was identical in the control and captopril groups, so extension of the non-ischemic myocardium was inhibited by captopril. In the present study, the infarct size was diminished by IP, thus the reduction in infarct size strongly influenced the extent of LV remodeling. Fig 4 shows the correlation between the extent of LV remodeling, which was expressed as the LV volume index of LVP at $20 \mathrm{mmHg}$, and the infarct size. Because we used IP and KATP openers to reduce infarct size, we cannot totally exclude that possibility that it is not only the infarct size-LV volume index relationship shown in Fig 4. However, IP and injection of KATP openers were performed only once before sustained ischemia and it has been shown that the topography of myocardial salvage does not differ between earlier reperfusion, IP and KATP openers. Therefore, it is likely that the relationship in Fig 4 is applicable to infarct size limitation by the earlier reperfusion. Nevertheless, a good correlation between the infarct size and LV volume index indicates that the infarct size is the most important determinant of $\mathrm{LV}$ remodeling in the ischemic-reperfused heart.

In the present study, the hemodynamic measurement at 3 weeks after reperfusion demonstrated that the LV end diastolic pressure was not elevated in all groups, in spite of the difference in infarct size. This result indicates that the compensation of the LV to the loss of myocardium was fully exerted. The LV remodeling may be a compensated process in this model and the lesser remodeling indicates attenuation of myocardial damage. It is important to consider where the myocardium is remodeled. In the ischemicreperfused model, there are 3 types of LV myocardium: the non-ischemic, ischemic but viable, and infarcted regions. As has been shown, the infarcted region becomes a scar and usually shrink in 3 weeks. Thus, it is the ischemic but viable myocardium and the non-ischemic myocardium that play an important role in the remodeling, but how much each region affects the remodeling process could not be determined from the data in the present study. This should be further investigated.

The second of the major findings is that the mito-KATP channel openers, diazoxide and nicorandil, can mimic the effect of IP in terms of ventricular remodeling as well as reduction of infarct size. Because the selective blockade of the mito-KATP channels by 5-HD abolished the effect of diazoxide and nicorandil on both infarct size and LV remodeling, the opening of the mito-KATP channels is a crucial mechanism in the reduction of infarct size and attenuation of $\mathrm{LV}$ remodeling. The major mechanism of these drugs is the reduction in infarct size as demonstrated by the correlation in Fig 4.

Diazoxide has more effect on the mito-KATP channels than the sarcolemmal KATP channels, ${ }^{35}$ and it also acts strongly on the arterial smooth muscle KATP channels, which dilate the arterioles and cause systemic hypotention?6 Recent evidence shows that the vascular smooth muscle KATP channels are composed of Kir 6.1 or 6.2 with SUR2B subunits and that the cardiomyocyte sarcolemmal KATP channels consist of Kir 6.2 with SUR2A subunits? 37,38 Diazoxide is a potent $\mathrm{K}^{+}$channel-opening drug for constructed SUR1/Kir 6.2 and SUR2B/Kir 6.2 channels, but not for the SUR2A/Kir 6.2 channel ${ }^{39}$ The dose of diazoxide we used was almost the maximum that could be used in an in vivo study.

Nicorandil acts on both sarcolemmal and mito-KATP channels, ${ }^{40}$ and also has a nitrate effect.1 The effect of diazoxide was completely blocked by $5-\mathrm{HD}$, but its effect on nicorandil was not complete, as shown by Fig 4. This may be attributed to its combined effect, although it was small in the present study. However, Sanada et al showed that in a dog model, the sarcolemmal and mito-KATP channels were equally important in reducing infarct size 19 The species difference should be noted and we should be careful in extrapolating the data to humans. Recently it has been shown that nitric oxide accelerates the mito-KATP channel opening, 42 and it may be the nitric oxide effect of nicorandil that accelerates the mito-KATP channel opening. It remains to be determined how important this effect of nicorandil is on the opening of mito-KATP channels.

We conclude that chronic LV remodeling after an ischemia-reperfusion insult was suppressed by IP and by mito-KATP channel openers, with a concomitant reduction of the size of the histologically determined infarct after 3 weeks of reperfusion.

\section{Acknowledgments}

This study was supported in part by research grant from the Ministry of Education, Science and Culture of Japan. We wish to thank Ms Rie Ishihara and Ms Kazuko Iwamoto for their excellent technical assistance.

\section{References}

1. Murry CE, Jennings RB, Reimer KA. Preconditioning with ischemia: A delay of lethal cell injury in ischemic myocadium. Circulation 1986; 74: 1124-1136.

2. Auchampach JA, Grover GJ, Gross GJ. Blockade of ischemic preconditioning in dogs by the novel ATP dependent potassium channel antagonist sodium 5-hydroxydecanate. Cardiovasc Res 1992; 26: $1054-1062$.

3. Baker JE, Holman P, Gross GJ. Preconditioning in immature rabbit hearts: Role of KATP channels. Circulation 1999; 99: 1249-1254.

4. Fryer RM, Eells JT, Hsu AK, Henry MM, Gross GJ. Ischemic preconditioning in rats: Role of mitochondrial KATP channel in preservation of mitochondrial function. Am J Physiol 2000; 278: H305-H312.

5. Garlid KD, Paucek P, Yarov-Yarovoy V, Murray HN, Darbenzio RB, D'Alonzo AJ, et al. Cardioprotective effect of diazoxide and its interaction with mitochondrial ATP-sensitive $\mathrm{K}^{+}$channels. Circ Res 1997; 81: $1072-1082$.

6. Garlid KD, Paucek P, Yarov-Yarovoy V, Sun X, Schindler PA. The mitochondrial KATP channel as a receptor for potassium channel openers. J Biol Chem 1996; 271: 8796-8799.

7. Gross GJ, Fryer RM. Sarcolemmal versus mitochondrial ATP-sensitive $\mathrm{K}^{+}$channels and myocardial preconditioning. Circ Res 1999; 84: 973-979.

8. Liu Y, Sato T, O’Rourke B, Marban E. Mitochondrial ATP-dependent potassium channels, novel effectors of cardioprotection? Circulation 1998; 97: 2463-2469.

9. McCullough JR, Normandin DE, Conder ML, Sleph PG, Dzwonczyk $\mathrm{S}$, Grover GJ. Specific block of the anti-ischemic actions of cromakalim by sodium 5-hydroxydecanate. Circ Res 1991; 69: 949958.

10. Sato T, Sakai N, O'Rourke B, Marban E. Nicorandil, a potent cardioprotective agent, acts by opening mitochondrial ATP-dependent potassium channels. J Am Coll Cardiol 2000; 35: 514-518.

11. Wu DJ, Minatoguchi S, Uno Y, Arai M, Wang N, Nishida Y, et al. Combination of N-methyl-1-deoxynojirimycin and ischemic preconditioning markedly reduces the size of myocardial infarcts in rabbits. Jpn Circ J 2001; 65: 673-677.

12. Yasuda T, Hashimura K, Matsu-ura Y, Kato Y, Ueda T, Mori I, et al. Nicorandil, a hybrid between nitrate and ATP-sensitive potassium channel opener, preconditions human heart to ischemia during percutaneous transluminal coronaryangioplasty. Jpn Circ J 2001; 65: 526530.

13. Chareonthaitawee P, Christian TF, Hirose K, Gibbons RJ, Rumberger JA. Relation of initial infarct size to extent of left ventricular remodeling in the year after acute myocardial infarction. J Am Coll Cardiol 1995; 25: 567-573.

14. Lee KS, Marwick TH, Cook SA, Go RT, Fix JS, James KB, et al. Prognosis of patients with left ventricular dysfunction, with and without viable myocardium after myocardial infarction: Relative efficacy of medical therapy and revascularization. Circulation 1997; 
90: $2687-2694$.

15. Jaburek M, Yarov-Yarovoy V, Paucek P, Garlid KD. State-dependent inhibition of the mitochondrial KATP channel by glyburide and 5hydroxydecanoate. J Biol Chem 1998; 273: 13578-13582.

16. Joyeux M, Godin-Ribuot D, Ribuot C. Resistance to myocardial infarction induced by heat stress and the effect of ATP-sensitive potassium channel blockade in the rat isolated heart. Br J Pharmacol 1998; 123: $1085-1088$.

17. Pfeffer JM, Pfeffer MA, Fletcher PJ, Braunwald E. Progressive ventricular remodeling in rat with myocardial infarction. Am J Physiol 1991; 260: H1406-H1414.

18. Cohen MV, Yang Xi-M, Downey JM. Smaller infarct after preconditioning dose not predict extent of early functional improvement of reperfused heart. Am J Physiol Heart 1999; 277: H1754-H1761.

19. Miura T, Liu Y, Kita H, Ogawa T, Shimamoto K. Role of mitochondrial ATP-sensitive $\mathrm{K}^{+}$channels and PKC in anti-infarct tolerance afforded by adenosine A1 receptor activation. J Am Coll Cardiol 1999; 35: $238-245$

20. Sanada S, Kitakaze M, Asanuma H, Harada K, Ogita H, Node K, et al. Role of mitochondrial and sarcolemmal KATP channels in ischemic preconditioning of canine. Am J Physiol 2001; 280: H256-H263.

21. Schultz JEJ, Hsu AK, Gross GJ. Ischemic preconditioning in the intact rat heart is mediated by $\sigma 1$ but not $\mu$ - or K -opioid receptors. Circulation 1998; 97: 1282-1289.

22. Wang Y, Hirai K, Ashraf M. Activation of mitochondrial ATP-sensitive $\mathrm{K}^{+}$channel for cardiac protection against ischemic in jury is dependent on pr otein kinase C acticivity. Circ Res 1999; 85: 731 741.

23. Fishbein MC, Meerbaum S, Rit J, Lando U, Kanmatsuse K, Mercier $\mathrm{Jc}$, et al. Early phase acute myocardial infarct size quantification: Validation of the triphenyl tetrazolium chloride tissue enzyme staining technique. Am Heart J 1981; 101: 593-600.

24. Cohen MV, Yang Xi-M, Neumann T, Heusch G, Downey JM. Favorable remodeling enhances recovery of regional myocardial function in the weeks after infarction in ischemically preconditioned hearts. Circulation 2000; 102: 579-583.

25. Zardini P, Marino P, Golia G, Anselmi M, Castelli M. Ventricular remodeling and infarct expansion. Am J Cardiol 1993; 72: 98-106.

26. Morishima I, Sone T, Okumura K, Tsuboi H, Kondo J, Mukawa H, et al. Angiographic no-reflow phenomenon as a predictor of adverse long-term outcome in patients treated with percutaneous transluminal coronary angioplasty for first acute myocardial infarction. $J \mathrm{Am}$ Coll Cardiol 2000; 36: $1202-1209$.

27. Sakata Y, Kodama K, Komamura K, Lim YJ, Ishikura F, Hirayama A, et al. Salutary effect of adjunctive intracoronary nicorandil administration on restoration of myocardial blood flow and functional improvement in patients with acute myocardial infarction. Am Heart $J$ 1997; 133: 616-621.

28. Iwakura K, Ito H, Kawano S, Shintani Y, Yamamoto K, Kato A, et al. Predictive factors for development of the no-reflow phenomenon in patients with reperfused anterior wall acute myocardial infarction.
J Am Coll Cardiol 2001; 38: 472-477.

29. Shimizu M, Wang QD, Sjoquist PO, Rydem L. The angiotensin II AT1-receptor antagonist candesartan improves functional recovwry and reduces the no-reflow area in reperfused ischemic rat hearts. $J$ Cardiovasc Pharmacol 1999; 34: 78-81.

30. Wang WZ, Anderson G, Firrell JC, Tsai TM. Ischemic preconditioning versus intermittent reperfusion to improve blood flow to a vascular isolated skeletal muscle flap of rats. J Trauma 1998; 45: 953-959.

31. Okamura T, Miura T, Iwamoto H, Shirakawa K, Kawamura S, Ikeda $\mathrm{Y}$, et al. Ischemic preconditioning attenuates apoptosis through protein kinase C in rat hearts. Am J Physiol 1999; 277: H1997-H2001.

32. White HD, Norris RM, Brown MA, Brandt PWT, Whitlock RML, Wild CJ. Left ventricular end-systolic volume as the major determinant of survival after recovery from myocardial infarction. Circulation 1987; 76: 44-51.

33. Pfeffer MA, Pfeffer JM, Steinberg C, Finn P. Survival after an experimental myocardial infarction: Beneficial effects of long-term therapy with captopril. Circulation 1985; 72: 406-412.

34. Pfeffer MA, Braunwald E, Myoe LA, Basta L, Browm EJ Jr, Cuddy TE, et al. On behalf of the SAVE investigators. Effect of captopril on mortality and morbility in patients with left ventricular dysfunction after myocardial infarction: Result of the survival and ventricular enlargement trial. $N$ Engl J Med 1992; 327: 669-677.

35. Sato T, Sasaki N, Seharaseyon J, O'Rourke B, Marban E. Selective pharmacological agents implicate mitochondrial but not sarcolemmal KATP channels in ischemic cardioprotection. Circulation 2000; 101: $2418-2423$.

36. Powell WJ, Green RM, Whiting RB, Sanders CA. Action of diazoxide on skeletal muscle vascular resistance. Circ Res 1971; 28: 167-178.

37. Yokoshiki H, Sunagawa M, Seki T, Sperelakis N. ATP-sensitive $\mathrm{K}^{+}$ channels in pancreatic, cardiac, and vascular smooth muscle cells. Am J Physiol 1998; 274: C25-C37.

38. Pluja L, Yokoshiki H, Sperelakis N. Evidence for presence of ATPsensitive $\mathrm{K}^{+}$channels in rat colonic smooth muscle cells. Can $J$ Physiol Pharmacol 1998; 76: 1166-1170.

39. Yokoshiki H, Sunagawa M, Seki T, Sperelakis N. Antisense oligodeoxynucleotides of sulfonylurea receptors inhibit ATP-sensitive $\mathrm{K}^{+}$channels in cultured neonatal rat ventricular cells. Pflugers Arch 1999; 437: 400-408.

40. Davie CS, Kubo M, Standen NB. Potassium channel activation and relaxation by nicorandil in rat small mesenteric arteries. Br J Pharmacol 1998; 125: 1715-1725.

41. Pieper GM, Gross GJ. Salutary action of nicorandil, a new antianginal drug, on myocardial metabolism during ischemia and on postischemic function in a canine preparation of brief, repetitive coronary artery occlusions; comparison with isosorbide dinitrate. Circulation 1987; 76: 916-928.

42. Sasaki N, Sato T, Ohler A, O'Rourke B, Marban E. Action of mitochondrial ATP-dependent potassium channels by nitric oxide. Circulation 2000; 101: 439-445. 